\title{
Sustainable Approaches to A Reform of Coal Mining Industry in Serbia
}

\author{
Maja Mitich \\ University Singidunum, Belgrade, Serbia \\ E-mail:miticmaja@ptt.rs
}

\begin{abstract}
Societies in transition focus on a set of specific aspects of sustainability critical to their efficient and effective transformation. The complexity of transitional process is defined by radical changes occurring in the domain of privatization, intensive technological change, business strategy and competitiveness, developing markets and infrastructure with the overall concern for the well being of all interested and involved groups and environmental issues. Currently, in many mining companies in Serbia, privatization process is still active and in this paper we review some of examples of sustainable strategies that have been developed for the reform process of coal mining industry in Serbia. We examine how earlier mentioned factors are integrated into these strategies and at the end give recommendations for their more effective application on the basis of sustainable technology management and development principles.
\end{abstract}

Keywords: Sustainability, Mining industry, Sustainable technology management and development principles

\section{Introduction}

Sustainability can be described as a state in which humankind is living within the carrying capacity of the earth. This means that the earth has the capacity to accommodate the needs of existing populations in a sustainable way and is therefore also able to provide for future generations. Humankind is nowadays facing the fact that, with its intensive industrial activities, pollution, and resource exploitation has exceeded the earth's carrying capacity. We must make strong and concerted shift of development in direction where earth can sustain humankind needs. This concerted and integrated action and change of direction can be referred to as sustainable development. Changes and integrated action can be first applied on micro level - sectors like mining industries, where cumulative effects of such small changes can give very good results, in terms of sustainable development.

Currently, in many mining companies in Serbia, privatization process is still active and in this paper we review some of examples of sustainable strategies that have been developed for the reform process of coal mining industry in Serbia. Paper also discusses how sustainability principles can be applied to the mining industry and resulting remarks can further serve as a guidance for development of sustainable approaches in other regions with similar situations.

\section{Sustainable development objectives}

A review of literature on sustainability suggests that sustainability can be described in terms of social, economic and environmental states that are required in order for overall sustainability to be achieved. The World Summit on Sustainable Development Plan of Implementation provides range of sustainable development objectives that should be aimed in order to achieve sustainability.

Environmental Sustainable Development Objectives:

- Size, productivity and biodiversity: Ensure that development conserves or increased the size, biodiversity and productivity of the biophysical environment.

- $\quad$ Resource management: Ensure that development supports the management of the biophysical environment.

- $\quad$ Resource extraction and processing: Ensure that development minimizes the use of support of environmentally damaging resource extraction and processing practices.

- Waste and pollution: Ensure that development manages the production of waste to ensure that this does not cause environmental damage.

- Water: Ensure that development manages extraction, consumption and disposal of water in order not to adversely affect the biophysical environment.

- Energy: Ensure that development manages the extraction and consumption of resources in order not to adversely affect natural systems (Gibbert, 2005).

Economic Sustainable Development Objectives: 
- $\quad$ Employment and self-employment: Ensure that development supports increased access to employment and supports self-employment and the development of small enterprises.

- $\quad$ Efficiency and effectiveness: Ensure that development (including technology specified) is designed and managed to be highly efficient and effective, achieving high productivity level with few resources and limited waste and pollution.

- Indigenous knowledge and technology: Ensure that development takes into account and draws on, where appropriate, indigenous knowledge and technology.

- $\quad$ Sustainable accounting: Ensure that development is based on a scientific approach that takes in to account, and is formed by, social, environmental and economic impacts.

- An enabling environment: Develop an enabling environment for sustainable development including the development of transparent, equitable, supportive policies, processes and forward planning.

- $\quad$ Small-scale, local and diverse economies: Ensure that development supports development of small-scale, local and diverse economies, (Gibbert, 2005).

Social Sustainable Development Objectives:

- Access: Ensures that development supports increased access to land, adequate shelter, finance, information, public service, technology and communications where this is needed.

- Education: Ensure that development improves levels of education and awareness, including awareness of sustainable development.

- Inclusive: Ensure that development processes, and benefits, are inclusive.

- Health, Safety and Security: Ensure that development considers human rights and supports improved health, safety and security.

- $\quad$ Participation: Ensure that development supports interaction, partnerships and involves and is influenced by the people that it affects.

This description provides simple definitions for sustainability and sustainable development. A useful aspect of the definition is that it provides both an ultimate state that must be strived for a swell set of actions or objectives, which if addressed and implemented, will lead towards this state (Gibbert, 2005).

\section{Challenges of mining industry in the process towards sustainability}

Creating the sustainable and feasible development strategy takes into account the diversified needs and goals and strongly relies on the effort to evaluate the internal strengths and resources from the perspective of their competitive capacity. Traditionally, valuable, rare, non-substitutable and non-imitable resources represent key factors that create and maintain an advantageous position with respect to competitors (Barney, 2004).

Today, a lot of industries, in order to support sustainable development need some extensive reforms, especially with aim to stay/become competitive. Mining industry for itself is facing a lot of challenges on the road towards sustainability, which can be divided, as follows:

Environmental challenges:

- $\quad$ Erosion, landslides, soil instability,

- $\quad$ Remediation of old sites,

- $\quad$ Storage of different waste types,

- Mine waste waters,

- Chemical safety at operations,

- Use of ozone depleting substances,

- $\quad$ Energy (in)efficiency,

- $\quad$ Protection of bio - and geodiversity (Portfolio committee meeting presentation, School of Mining Engineering, University of the Witwatersrand, 2000).

Social and economic challenges:

- $\quad$ Small scale mining

- $\quad$ Poverty and jobs

- $\quad$ Training and education 
- Technological achievements and innovations

- Gender issues in mining

- Community participation in decision making

- Mineral ownership and evaluation

- $\quad$ Post mine closure

- $\quad$ Employment

- Resettlement

- $\quad$ Corporate responsibility. (Portfolio committee meeting presentation, School of Mining Engineering, University of the Witwatersrand, 2000).

All these challenges need to be mitigated and facilitated effectively, where one way is through development, translation and application of the principles of Sustainable Development (SD) into principles of Sustainable Technology Management \& Development (STMD). But first, we can take a look on similar work with regard to the use of sustainable development principles in the context of mining and we can see that there are still some initiatives in progress. Of particular note are the Global Reporting Initiative standards. Recently there have been developed Sustainability Reporting Guidelines \& Mining and Metals Sector Supplement (2009). The guidelines propose the identification of different:

1) Economic Performance Indicators

2) Environmental Performance Indicators

3) Social Performance Indicators:

- Labor Practices and Decent Work;

- Human Rights;

- Society;

- Product Responsibility;

which can serve as an orienteer for decision makers in organization and lead to an improved refocusing of organization towards sustainability and higher environmental performance. A special attention is given to report process since some researches show that while there is evidence of increasing sophistication in the development of social and environmental disclosure in the biggest world mining companies, there is considerable variation in the maturity of reporting content and styles of these companies (Jenkins and Yakovleva, 2006).

Another tool that should be also emphasized is the application of ISO 14031 standards. It brings into focus central aspects related to the construction and use of environmental performance indicators (EPIs) and their application in industrial companies. EPIs may be used on a macro level by external stakeholders for regulatory, control, influence and risk minimization purposes. They may also be used on a micro level inside the company for goal setting, control and surveillance of product performance and performance of manufacturing and administrative processes, as well as for benchmarking purposes by comparing own performance vs. competitors' performance or vs. branch average process and product performance (Thoresen, 1999).

Transitional process brings to industries a lot of challenges, in every sector, and as already emphasized they have environmental, social and economic aspects. In order to mitigate efficiently recognized challenges we need to formulate objectives of reform process, since they specify the directions for improvement. It is essential, in the process of determining which operative measures we must apply to accomplish reform goals.

Environment: Challanges $\rightarrow$ Reform Objectives $\rightarrow$ Performance Indicators

Society: Challenges $\rightarrow$ Reform Objectives $\rightarrow$ Performance Indicators

Economy: Challenges $\rightarrow$ Reform Objectives $\rightarrow$ Performance Indicators

These approaches can be integrated and serve for development of methodology, where is implied identification of suitable indicators (on the merit of defined objectives) that quantitatively and qualitatively can help in estimation of our progress towards sustainability.

Also, considerations of ICMM (International Council on Mining and Metals) sustainable development framework should be taken into account since it provides directions where implementation of SMTD principles can be developed. It suggests:

- Work on development of effective regulations and procedures that can facilitate the mining, minerals in collaborations with governments, industry, public and other stakeholders; 
- Design and implementation standards that will assure continual improvement, preventions mitigate and minimize various environmental impacts;

- In area or risk management design and implementation of adequate risk management systems with information dissemination (inform potentially affected parties of significant risk from mining, minerals and other similar operation);

- $\quad$ Respect conservation of biodiversity and cultural heritage;

- $\quad$ Remediate degraded land affected or occupied by operations;

- $\quad$ Popularize, promote and support the development of integrated land use planning and mining exploration;

- $\quad$ Provide adequate waste management system (storage and disposal of residual and hazardous waste);

- $\quad$ Separate waste and where possible apply recycling;

- Conduct and support innovation that focuses on the use of products and technologies that are safe and efficient in the use of energy, natural sources and other materials;

- $\quad$ Design adequate work safety procedures with strictly defined responsibilities and trainings;

- Integrate social and economic needs into all above mentioned principles which shall contribute to community development, protection and above all tolerance and cooperation in areas where mining operations are conducted, (International Council on Mining and Metals, 2003).

\subsection{Sustainable technology management and development principles}

Sustainable competitiveness means the achievement of a set of different goals - economic and non-economic, meaning that it is a concept based on quantitative and qualitative performance indicators, namely, the integration of traditional performance goals measured by traditional economic indicators (e.g. profitability, GDP) and a set of new non-economic performance criteria that emphasize the satisfaction of needs of the customers, employees and all other stakeholders. The performance balanced scorecard approach is based on the efforts to build sustainable competitiveness taking into account multiple factors (Meyer, 2002).

The next table (1) shows the results of the effort to relate the proclaimed principles of sustainable development of society and sustainable technology management (Rainey, 2006). All this defined principles can be effectively applied in various industries such as mining industry.

In Serbia for instance, many coal mining sites are facing a lot of environmental and economic problems which clearly indicate the need for their reforms and there lies the opportunity for application of SMTD principles.

Identified environmental problems are as follows:

1) Mine waters generated from the underground operations (maximum values in spring and fall can reach over 5.0 $\mathrm{m}^{3} / \mathrm{min}$ on some sites) in some cases can contain a large freight of suspended fines (coal, clay), as well as occasional traces of oil, fuel and grease. The water is usually discharged into nearest rivers and streams without treatment.

2) Old mechanization for coal exploitation and production.

3) Self ignition and combustion of residual coal content in the waste rock, which emits noxious fumes (in high concentrations the SOx content can be irritating and toxic) and has lead to complaints from local residents.

4) Surface deformations and sinkholes.

5) There are severe slope stability problems above the upper boundary of the explorations pits, which affect small settlements around the mining area. These sites are proclaimed to be of high risk since they can induce forming of landslides.

6) Improperly stored hazardous waste;

7) The huge size of waste dumps and the low percentage of rehabilitated areas (for example in the Kolubara basin, waste from four coal mines occupies an area of 3,481 ha, of which only $36 \%$ has been recultivated; in Kostolac, waste from three mines is deposited over a total surface of 1,479 ha of which only $34 \%$ has been rehabilitated and the situation is similar with other coal mining sites in Serbia);

8) Other problems are also related to coal bed methane, (Ministry for protection of natural resources and environment, 2003).

\subsection{Application of STMD in mining industry}

What is important here is that identified environmental problems cannot be analyzed selectively, without taking a deep reflection on social and economical status of communities where mining sites are located. Social end economic problems are seen in facts that coal mines historically have great role and huge importance, in the first place in economical development of local communities where they are positioned, mostly in central and eastern Serbia. 
Development of this industrial centers was followed by the increase in population and closely related to the fact that mining industry has dominating part in the forming of GDP during last five decades. Especially difficult circumstances are that municipalities where the mines are located belong to the least developed in Serbia. Even 4 municipalities have GDP below the $50 \%$ and have unemployment rate with almost $24 \%$. As a result of over a decade of low prices and minimal investment, the Serbian coal industry is now in a difficult situation. Prices are less than half the level needed for short-term cost recovery, which is estimated at US\$ 6.4/ton. Production costs, including maintenance, depreciation and expropriation, total approximately US\$ $11 /$ ton. In such atmosphere, every change is seen as a threat and fear that the conditions might get worse, which induces also certain social tensions, (Ministry for protection of natural resources and environment, 2003).

For example, established in 1853, Senje is Serbia's oldest coal mine, complete with shafts, workshops and administrative buildings. The mine is part of an ensemble which also includes houses, a school, a house of culture, a railway station, a church, museum and a hospital, many of which are still in use.

This is a typical industrial community of the 19th-20th centuries, now in economic and physical decline, in need of new sources of income and employment. The mine is still in operation, but it is estimated that coal reserves will run out in seven to ten years with a consequent risk of depopulation (Senje coal mine, integrated rehabilitation project plan/Survey on the architectural and archaeological heritage, 2003).

On the other hand, as it is recommended by STMD principles, we should look more closely to other values that this locality certainly hold and emphasized them as advantages. This would mean respect and development of relationships, interactions and interdependence between natural and cultural heritage and industrial operations, communication and acceptance of responsibility between public and relevant community institutions which would lead to nurturing of long term values.

The village is sited on the River Ravanica, in a hilly and surprisingly unspoiled landscape in central Serbia, south of Belgrade, in the vicinity of two famous medieval monasteries: Ravanica and Manasija. There is considerable potential here for tourism which could be encouraged as part of the regional development program through for example the establishing of an eco-museum, the restoration of the industrial buildings (particularly the shafts and the narrow-gauge railroad) and the overall transformation of a dying settlement into a cohesive tourist centre. (Senje coal mine, integrated rehabilitation project plan/Survey on the architectural and archaeological heritage, 2003). The historical significance of the mine is considerable since it is the oldest preserved industrial area in Serbia and in the period from the building of the railway in 1892 until 1941 it was one of the most prosperous industrial regions in the country. The mine shafts themselves - Alexander's Shaft of 1853, the first in Serbia, and the Main Shaft, still in use and retaining 19th century steam machinery and head-gear - are of outstanding national importance. Although the condition of many of the buildings at the mine and in the town is bad, and will continue to deteriorate, the majority at least survive. This survival, together with the well-preserved urban structure, the splendid cultural landscape and the solid documentation held in the local museum, joined with the industrial tradition of the population, offers an excellent basis for authentic restoration and the comprehensive rehabilitation of the whole ensemble, from the industrial buildings to the social and commercial. The necessary addition of new buildings for the accommodation of tourists must be done in a manner which respects the existing building pattern and character of the village. (Senje coal mine, integrated rehabilitation project plan/Survey on the architectural and archaeological heritage, 2003).

Senje Rudnik offers an excellent opportunity to achieve a sustainable development which respects the historic fabric of the mine and the village, and encourages new uses which enable the continuation in situ of the long-established community, but where industrial, environmental and social issues should be integratively defined. (Senje coal mine, integrated rehabilitation project plan/Survey on the architectural and archaeological heritage, 2003).

In that sense, it is important to note that in May 2008, "The strategy for Serbia sustainable development" has been adopted, where according to the existing state of mining in Republic Serbia, is recommended for sustainable development to be achieved through several distinctive sectoral goals:

- $\quad$ harmonizing regulative in mining area with EU legislative,

- $\quad$ successful finalization of transition phase in mining sector with additional participation of private sector and improvement in area of business economy,

- rational management of nonrenewable resources and restriction on illegal exploitations,

- application of technological solutions for minimizing the environmental impact of mineral resource exploitation,

- $\quad$ sustainable supply of market with mineral resources,

- $\quad$ industry development and employment rate increment with involvement of all stakeholders in decision making process, during the whole mining life cycle and later. 
It is also anticipated through "Strategy of development of Serbia mineral complex" which creation is still in progress, to further define instruments, measures and activities that could lead to achievement of long term goals in sustainable development of mining sector. As it can been seen, by following the Serbia Government vision about sustainable development of mining industry, by application and implementation effective programs and instruments, Senje coal mine can become one of representative localities in terms of reforms towards sustainability. In next chapter of this paper we will elaborate some of directions that can be followed with according established goals on the Senje example.

\subsubsection{Application of STDM principles in mining industry- example of Senje coal mine in Serbia}

Nowadays, some of mining sites in Serbia are due to be privatized, and they can be a very good starting point for implementation of mentioned principles and tools described earlier. By their application, not only the environmental problems can be effectively mitigated, but also more efficient operation, productiveness and competitiveness of mining industry can be achieved.

According to the results of analysis conducted through projects "Strategy for Serbia sustainable development", it is estimated that until 2014 approximately 26 millions of euros of investments in mining industry are needed, but what one must keep in mind is that these mining sites also characterize social and economic challenges that are domineering. It is obvious that integrative approach is needed to effective resolve these challenges.

Integrated rehabilitation project plan/Survey on the architectural and archaeological heritage for Senje mine anticipates:

- Immediate repairs and protection of the most important individual buildings.

- $\quad$ New, wider protection of the site (concept, plans, preparing study supporting legal acts).

- $\quad$ The town infrastructure repairing works, narrow gauge railroad;

- $\quad$ Preparing for a mining museum in situ, tourist accommodation facilities, etc.

- $\quad$ Establishing an eco-museum, concept, project design, management study, equipment, education programs and public awareness programs for inhabitants.

These are all good suggestions how some aspects of sustainable development can be mitigated, but still there are a lot of questions rising, especially economic issues due to transition and privatization process. Adequate form of privatization can introduce more effective managerial approach which can lead to paying more attention to eliminating waste, more efficient usage of resources and energy which would on the other hand enhance the increment of productivity. This opens the possibility for adequate restructuring of mine operations which brings direct economic benefits. Simultaneously new doors are open for investments in innovative and clean technology and implementation of continual environmental management system.

Some of activities that can be further implemented according to the STDM principles are:

1) The privatization process should be taken as a chance for existed potentials to be used, not only in direction of increase of economical efficiency, but also in the direction of integral environmental protection, (since that privatization has usually been seen as possibility for improvement in efficiency, competitiveness, management, product development and capital market, where the main focus is to decrease the pressure on the state budget that some companies are making). This process can usually bring and introduce new, innovative and clean technologies. A noticeable improvement in job quality, desirable from the point of view of social sustainability, is one of the major advantages of clean technologies (Getzner and Ritt, 2004).

2) Since privatization plans for coal industry in Serbia includes reduction in number of employees, different models and social programs should be developed and comprehensively presented to workers. This means defining the local criteria for sustainable outcomes, and activating organizational practices according to these criteria (Achterkamp and Vos, 2006). One, very important model of social program that can be developed is the one with aim that certain number of workers through intensive training programs can be trained for work on remediation and recultivation of mines and their waste dumps (with their own mechanization and engagement, mines could deliver greater part of projected activities, both on remediation process and building). As a part of this process, it is prerequisite to organize debates, counseling centers along the focus groups in all categories: managers, miners, citizens, stakeholders with aim for all structures in time to be introduced with possible options and solutions; this would "softer" the resistance towards privatization process that predominantly exists among citizens and workers. Implementation of such social programs could lead to lowering the costs of remediation and help on the minimizing of consequences of the increased unemployment rate due to privatization.

3) Life cycle assessment along with environmental risk assessment should be implemented to coal process production, since it can help on deriving the EPI indicators which could serve as the basis for defining action plans with tasks where certain improvements can be made, according to social, economic, and environmental local criteria. It will help to identify the most efficient and cost effective options for increasing the environmental performance of production 
process. Also, assessment of a company's operations and production processes should be conducted with aim to opportunities for efficiency improvements to be identified.

4) Social and economic benefits should be comprehensively presented to all stakeholders since, resolving environmental problems usually can bring improvements in infrastructure and on the other hand contributes to better life quality and better working and living standards.

5) Remediation, recultivation programs and landslide geotechnical measures and procedures can contribute to bringing houses and green surfaces to their original functions, which is the common interest of all residents in local communities that are affected by mining operations.

6) Establishing of the systematic monitoring of quality of all relevant environmental mediums (components) would be of great importance, because in real time observations of environmental quality parameters citizens and employees could be informed about the results of mine production, (especially important for their health quality and communal hygiene, because it would resolve many doubts concerning ecological issues that arise every day).

7) Continual communication among all interested parties in mine sites should be forced and improved; a reporting of mine activities should be more transparent and consult public opinion while making crucial decisions which can affect community as a whole.

\section{Conclusion}

The emphasis on sustainable technology management is related to the role of technology and its position at the core of all the business operations, and with focus on primary operations delivering value in the form of products and services to the customers, but also in satisfying the goals of the society, economy, local community, while simultaneously developing profitable business results (Levi-Jaksic, 2006). In this paper, only few facts and possible applications of sustainable development in mining coal industry have been discussed. More detailed and documented survey should be conducted in this area, but even with these narrow implications that have been presented here, it is clear that wide opportunities are lying in Serbian mining sector for its effective transformation towards sustainability.

\section{References}

Achterkamp M., Vos J. (2006). A framework for making sense of sustainable innovation through stakeholder involvement. International Journal of Environmental Technology and Management. Volume 6, Number 6.

Barney, J. B. (2004). Firm resources and sustained competitive advantage, Journal of Management, No 17.

Getzner M., Ritt T. (2004). Quantitative and qualitative employment impacts of environmental innovations. International Journal of Environmental Technology and Management, Vol. 4, No.4.

Gibberd J. T., (2005). Developing a Sustainable Development Approach for Buildings and Construction Processes Smart \& Sustainable Built Environments. Blackwell Publishing Ltd. Chapter 27. (pp 300-310).

International Council on Mining and Metals. (2003). ICMM sustainable development framework - ICMM Principles. Document Ref: C 020/290503.

Jenkins, H., Yakovleva, N.. (2006). Corporate social responsibility in the mining industry: Exploring trends in social and environmental disclosure. Journal of Cleaner Production, Volume 14, Issues 3-4.

Levi-Jaksic, M. (2006). The New Paradigm of Technology and Innovation Management, Management, No 43.

Meyer, M. (2002). Rethinking performance Management, Cambridge University Press.

Ministry of Culture and Media of the Republic of Serbia and the Ministry of Foreign Affairs of Serbia and Montenegro. (2003). Senje coal mine, integrated rehabilitation project plan/Survey on the architectural and archaeological heritage. Regional Programme for Cultural and Natural Heritage in South East Europe 2003 - 2006.

Ministry for protection of natural resources and environment. (2003). Report on the State of the Environment in Serbia, Belgrade.

Portfolio committee meeting presentation, School of Mining Engineering, University of the Witwatersrand. (2000) Environmental Management \& Sustainable Development in the Mining and Minerals Sector. [Online] Available: http://www.natural-resources.org/minerals/.

Rainey, D. (2006). Sustainable Business Development, Cambridge University Press, Cambridge.

Sustainability Reporting Guidelines \& Mining and Metals Sector Supplement, Version 6.0 of 12 January 2009. [Online] Available: http://www.globalreporting.org.

Serbia Government. (2008). The strategy for Serbia sustainable development. [Online] Available: www.srbija.gov.rs.

Thoresen J. (1999). Environmental performance evaluation - a tool for industrial improvement, Journal of Cleaner Production Volume 7, Issue 5. 


\section{Table Captions}

Table 1. Transforming the principles of Sustainable Development (SD) into principles of Sustainable Technology Management \& Development (STMD)

\begin{tabular}{|c|c|}
\hline SD & STMD \\
\hline Coexistence (the right to) & $\begin{array}{l}\text { Strategic enterprise thinking, "cradle to cradle" approach, balanced objectives; } \\
\text { strategies leading to followers approaching leaders; reducing technological gap; } \\
\text { life-cycle thinking; value chain approach; competency approach. }\end{array}$ \\
\hline Recognize interdependence & $\begin{array}{l}\text { Technological cooperation - vertical and horizontal relations; in - sourcing R\&D; } \\
\text { R\&D Consortia; technological fusion; competitive co-evolution. }\end{array}$ \\
\hline Respect relationships & $\begin{array}{l}\text { Value networks - business environment and natural world; Strategic technological } \\
\text { alliances and networking - synergetic effect. }\end{array}$ \\
\hline Accept responsibility & $\begin{array}{l}\text { Social responsibility - Integrity, Honesty, Enterprise Management; Leading } \\
\text { technological change with environmentally sound options, ecologically conscious } \\
\text { innovation ECI, finding the right measure of technological change in relation to } \\
\text { political, economic, social, technological and ecological factors - PESTE. }\end{array}$ \\
\hline Create long-term value & $\begin{array}{l}\text { Value creation, Create operations based on technologies that offer products and } \\
\text { services satisfying the needs of all the stakeholders. }\end{array}$ \\
\hline Eliminate wastes & $\begin{array}{l}\text { Continuous innovativeness and creativity, Life - cycle assessment - LCA; sustainable } \\
\text { technological products and processes. }\end{array}$ \\
\hline Rely on balanced solutions & $\begin{array}{l}\text { Openness, transparency, balanced score-card thinking; Strategic fit as balancing of } \\
\text { strategic and operations technological goals. }\end{array}$ \\
\hline Design limitations & $\begin{array}{l}\text { Risk mitigation; LCA; Risk assessment; Managing technological risk and threats at the } \\
\text { same time accepting the chances and challenges; technological forecasting. }\end{array}$ \\
\hline Continuous improvement & $\begin{array}{l}\text { Technological forecasting as the base for short }- \text { term/long }- \text { term plans and } \\
\text { technological strategies. }\end{array}$ \\
\hline
\end{tabular}

